\title{
'A Journey from the Vague to the Precise': using Faff's (2015) Pitching Research Framework for conveying our research ideas with a professional flair
}

\author{
Ritu Mohan ${ }^{\text {a1 }}$ \\ ${ }^{\text {a }}$ Bond University, Australia
}

\begin{abstract}
This paper explores the personal experience of using the Research pitch template, developed by Faff $(2015,2018)$, to develop a raw research idea of a novice researcher into a finished pitch, to share with and present to the expert, supervisor(s) for further discussion and guidance on the Research topic. The journey from the first encounter with the pitch template to metamorphosing into an expert user of the pitch, where we created various real and reverse engineered pitches at different stages of the learning curve, has been presented in detail with personal anecdotes as the process progressed.
\end{abstract}

Keywords: Pitching research, implied volatility, energy valuation

JEL code: G00

\section{Introduction}

The maxim, "A picture is worth a thousand words", somehow seems apt applied to the pitching research template. In the same spirit, it paints the thousand-word explanations (incidentally the word limit is of 1000 words, but still you get the point, same as when the Greek friends said about class, you know it was all Greek to me!) of something into a precisely edited version presented over a two-page template. Not perfect, just precise... to the point.

In a nutshell, that's exactly what the pitching template achieves, cuts out all the clutter and confusion. It puts all the important elements for a research proposal in an

${ }^{1}$ Corresponding author: Bond Business School, Bond University, Gold Coast, Australia, QLD 4229; email address: ritu.mohan@student.bond.edu.au 
orderly manner which forces us to think from a broad perspective about the topic and narrow it down to the most relevant aspects of our study by motivating us to think more deeply, logically and do more research about different aspects of the topic.

After many years working with the finance and IT industry, I am now beginning a career with academic research, things all new but not so new with a family background in professional education and research and almost everybody in the family having done their research in different fields of science or engineering. Personally, the energy sector has interested me for a while now and with the increased use of renewables around the world it's become even more so with the changing dynamics influencing their values and I intend to study in-depth the factors impacting its behaviour. That is the evolving idea I explore in the following pages using the Research pitch template.

The following sections are arranged as follows, Section 2 describes the initial interaction with the pitch template, Section 3 details the use of the pitch template (both "real" and "reverse engineered") section-wise entwined with personal experiences of using the pitch template in different situations, Section 4 Concludes with takeaways from the pitching template experience, Section 5 presents the completed pitch templates and associated idea novelty Venn diagrams for the Key paper and the Research idea paper, Section 6 presents the Acknowledgements, followed by the References used for this paper.

\section{First encounter with the pitching template}

Our first encounter with the pitching template was via the Pitching Research paper (Faff, 2017) which was the recommended pre-reading for the Research process in business course (conducted by the University of Queensland), and of its use through the many versions of Fantasy Pitching exercise. This particularly piqued our interest in it and its application in an informal setting, even before we got started with our first module.

This proved to be an ingenious way of easing the anxiety of grasping something complex that was to be applied to the dense research topics in order to make them more comprehensible to us and those we discussed it with. We were to come up in groups with a list of research ideas from current issues from news or from our own experience and then narrow them down to best few where at least one was a somewhat non-sensical approach to something making it humorous and this is the one that we applied the pitch template to.

The participants were excited to apply their own such ideas in this manner, where we went over each element of the template in detail and each group made a presentation of their understanding as well with our first ever practical application of the method 
creating a new version of the fantasy pitching in the process. This got us started on the right note and now it was time to further the process by applying the same to actual work - key and seminal, from our respective research areas.

\section{Implementing the pitching template}

A brief description of the pitching template helps put the following description into perspective,

The 4-3-2-1, countdown begins, the essential 4 elements come in the beginning Working Title, Basic Research Question, Key papers (3), Motivation/Puzzle. Followed by 3 elements of the Core pitch - Idea, Data and Tools, the 2 elements of the core pitch - What's new? and So What? and the final 1 element that completes the core pitch - Contribution? An additional supplementary item includes the Other Considerations.

The first serious exercise was to choose a Key paper from the Research area and gain a thorough understanding of it, then present it on the pitching research template under the items as presented above by taking apart information from the paper as it would fit under each category, which meant decoding a completed research work, and hence the appropriate name of Reverse Engineered (RE) Pitch. I chose K. Wangs paper titled "Volatility linkages of the equity, bond and money markets: an implied volatility approach" (Table 1) published in an 'A' ranked journal, which forms a key paper for my study as the technique proposed by Wang can potentially be applied to any different asset markets with the same robustness of results.

So, I read the paper, multiple times and then tried to use the Pitching Research Cue Card (the template Provided by Robert Faff with cues above each item, about what should be included in that specific category) that would give me a clue about what information to look for in the paper. The working title was easy, use the full APA reference, figuring out the basic research question for this paper was also not too difficult but phrasing it in a sentence incorporating the right information without leaving out anything in a way it made sense took some effort to achieve and gave a good idea about what exact question was being addressed in the study, that could be used to check against the results obtained. The 3 key papers could be picked out of their reference list, those that were used for most part of the research study.

The second exercise was to choose a seminal work related to our topic and I chose the paper written by Black and Scholes presenting their famous Option Valuation Formula "The Pricing of Options and Corporate Liabilities,", which again was a Reverse Engineered (RE) pitch for the famous piece of work and required a very different kind of approach, since it is not a standard empirical research where the pitch works very well. Here I had to decode the theoretical derivation of a financial 
formula fitting the approach they took to the elements of our pitching template. Here again the Working title was inserting the full APA reference of the paper. And the Research question, again required reading and re-reading of the paper and working out what exactly if presented as a central question were they trying to achieve. But once the job is done, it looks like it must have been plainly evident. Well, after understanding the derivation of the formula, it was not really that difficult. Two out of the three key papers were easy to pick from the motivation/puzzle section and the 3rd was obvious too, as they had used it to present an alternate derivation of their formula using this another famous work by William Sharpe.

After having done these two reverse engineered pitches, we set out to work on our own Research idea pitch (Table 2), so this time around we had no published papers to refer to as our cheat sheets to fill in each category but had to work out the different categories based on our experience working with the above RE pitches and still taking clues from the cue card to fill in the appropriate information about each element important to the Research proposal. This time the challenge was different from before where we needed to have a very thorough understanding of what had been done. This time around it was to understand what work had already been done in our field and shortlist the 3 most important papers that were contributing to our own study. Figure out what exact question we needed to answer (the Research question) that would give an appropriate outcome, think of the most appropriate Working title that would convey what we intended to do in all its manifestations in as few words as possible.

Until now it was easy to stay within the acceptable word limit. The motivation/puzzle section was where the actual motivation to work on the topic had to be described. For the key paper, it could be done within the suggested one paragraph, but for the Seminal paper, it was the key area that defined the flow of their work from previous works. The paper had taken inspiration from these and flowed as a natural progression from them and despite using the most succinct way to define it could not be contained in too few words. Our own Research pitch followed the word limit stipulation in the overall paper, not because there are no results or completed studies to cover, but also because we had learnt how much information is best to put for the first discussion on the Research proposal. This section followed naturally from the Research question and our inspiration from what prior work had been done in the field.

The most important section defining the Idea, Data and Tools was not that difficult after having understood the respective paper well and having completed the pre-pitch section, the idea was to define what the core theme was that drove the whole research study. Identifying the data also proved straight forward coming from the Data section in the paper for the key paper, but how much to include often breached the word limit boundaries. For the seminal paper, it being a valuation formula required some creative thinking to figure out what could be termed as data in this case, i.e. what are 
the essential ingredients on which the outcome of the study depended. As the Research idea uses a combination of the methods used in the two papers used for RE pitches it was clear what could be defined as data for my research study. The tools used are generally the methods implemented to obtain the results that can be analysed, and outcome defined. Tools for the key paper were easily identifiable, and for the Seminal paper, the straightforward thing to do was to apply all the methods until the formula was arrived at. Again, for the Research idea pitch being a combination of the methods used in the above two studies, it became easy to figure out all the methods that would be needed to get results from and to analyse the data being used.

The What's new? and So What? sections called for finding the information relating to what new work was being done by these studies that had not yet been done. It is an outcome of the literature review on all the existing works related to the topic. Use of the Mickey Mouse diagram for research idea novelty, which is essentially a Venn diagram representing the three pillars of the study whose novelty is the point of intersection of the main pillars, facilitates the defining of the key area of the study and what new idea it contributes to (Figure $1 \&$ Figure 2). The So what section gives the impact the studies have had on the markets, market participants, academic literature etc. and for the study still being done, is the expected influence it will have on different stakeholders.

The Contribution section needs a clear description of the practical and theoretical impact the study has had/will have, clearly presented in about three or so points taking reference from the study. The key paper more generically defined its contribution, whereas for the seminal paper the contributions of the work have been phenomenal and for want of accuracy were taken from another published paper about the contributions of the works of these famous scientists who had discovered the formula. For the Research idea pitch, the potential contributions were clearly defined taking specific references from the proposed research study.

Finally, the supplementary item of Other considerations, made us think critically about all the other considerations associated with any research study that might be a source of positive impact or of possible risks that could be encountered once the study is commenced, has reached a critical stage or is near completion when it might jeopardize the whole effort if not taken cognizance of in advance, need to be recognized and defined so proper action could be taken in time. Having assessed the Other considerations for the two reverse engineered papers, I had a good enough clue about what to look for concerning the positive aspects or risks for my own Research Idea. 


\section{Conclusion}

The pitching Research template ingrained a disciplined thinking process through a methodical approach (linear or non-linear) that proved a major influence on the outcome of our discussion of our proposed Research work with our respective supervisors. It enhanced the mutual understanding on what was being proposed and propagated an enriched discussion in a much shorter time frame with more focused and sensible exchange about the topic. In my case, it was evident from just the pitch document, the route I was proposing to take for my research work. My personal recommendation would be, familiarity with the Pitching Research Template and gaining expertise in its use should be a priority for every new researcher right at the start of their research voyage.

\section{Acknowledgements}

I wish to acknowledge, Tom Smith and Robert Faff for their mentoring and guidance which resulted in getting the Research idea off the ground and the Research study off to a successful start.

I was immensely fortunate to have the valuable guidance from an expert like Tom Smith in the field, right at the early stage of commencing my research study, with his advice regarding the best way to approach the topic under study and on how to proceed with the Research in gradual phases; as well as receiving useful feedback on the pitches as we progressed with applying the reverse engineered pitch on a key paper and seminal paper related to our field of work and finally the actual development of our own research idea presented through the pitch template.

It was hugely beneficial taking the Research Process in Business course with Robert Faff as the first Ph.D. course on our research degree program, of which practically gaining expertise on the use of the pitch was also a part of, where Robert facilitated our understanding and expectations of the Research process ahead of us and a good grounding on what to expect from a career in Research; regarding the pitch template his explaining of the process during the course, and taking us through every stage of the process with his insightful feedback and guidance as we gradually progressed from stage to stage proved valuable assets. 
'A Journey from the Vague to the Precise': Using Faff's (2015) Pitching Research Framework for Conveying our Research Ideas with a Professional Flair

Table 1. Completed 2-Page Pitch Template on "Volatility Linkages of the Equity, Bond and Money Markets, an Implied Volatility Approach." (reverse engineered pitch)

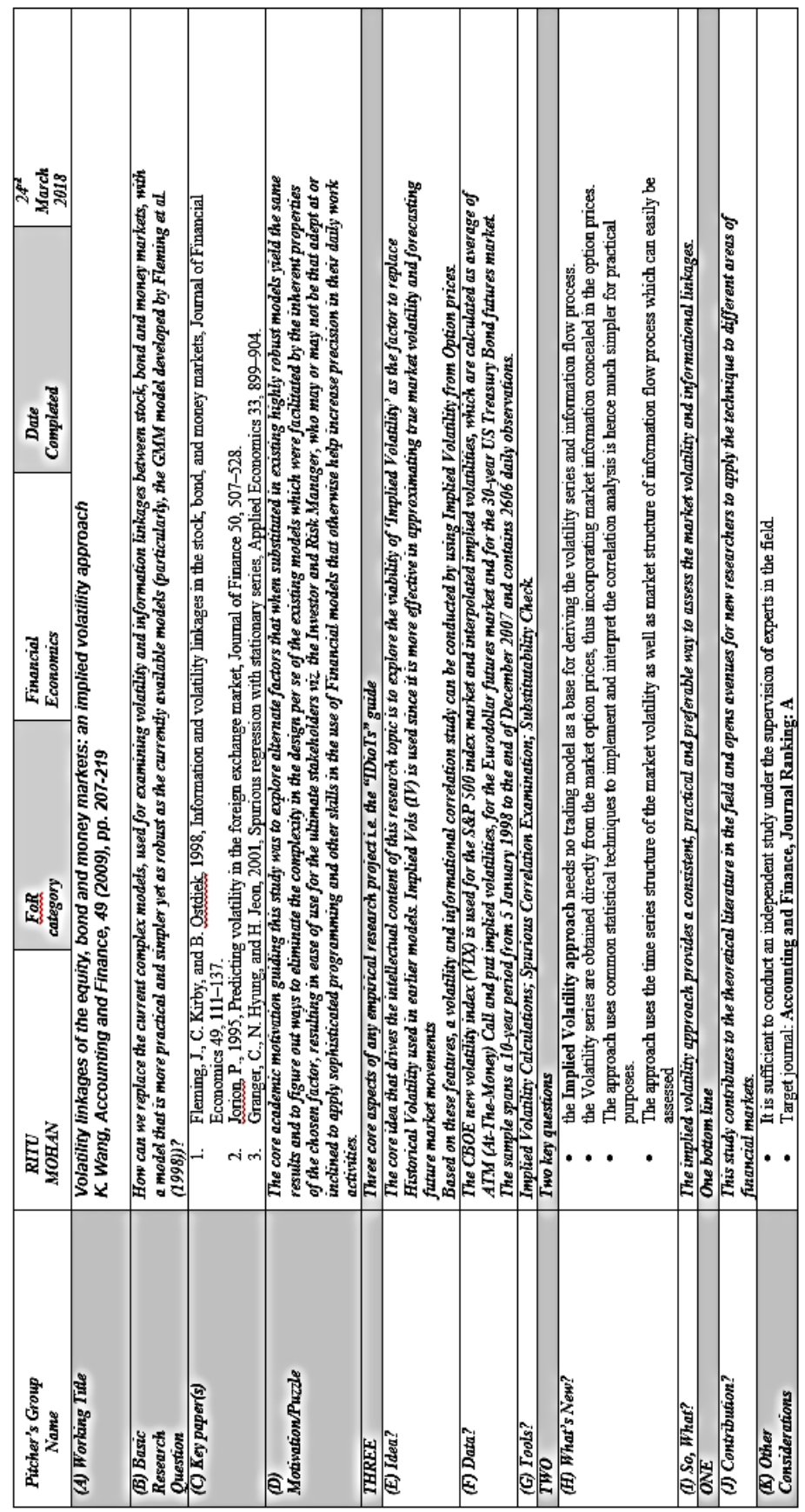

Vol. 17, No. 4 
Table 2. Completed 2-page pitch template on "A proposed energy price assessment model based on interactions between various traditional and renewable energy markets linked through their implied volatilities." (real pitch)

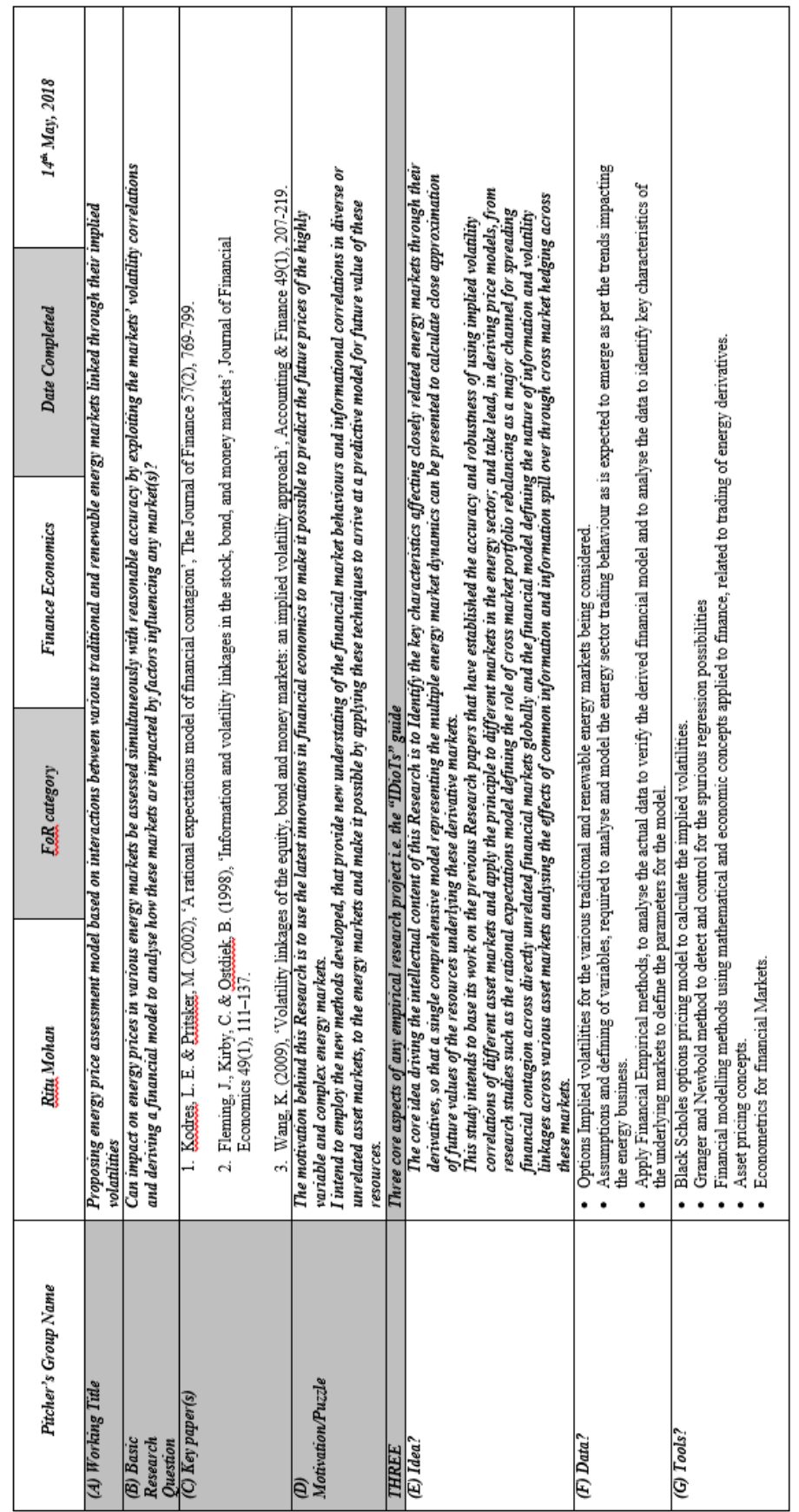


'A Journey from the Vague to the Precise': Using Faff's (2015) Pitching Research Framework for Conveying our Research Ideas with a Professional Flair

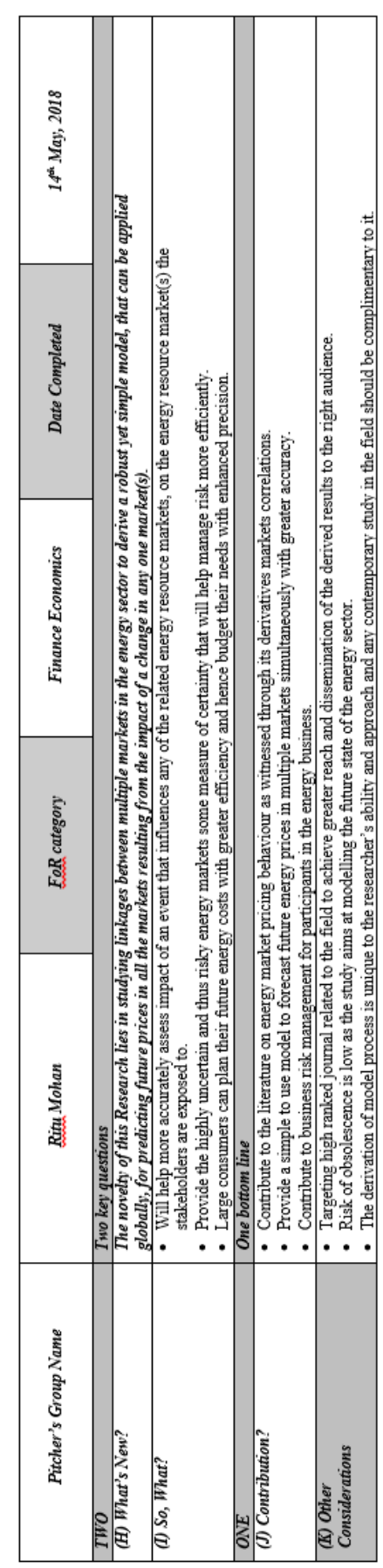

Vol. 17, No. 4 
Figure 1. Mickey Mouse Diagram Characterising Novelty of Research Idea (for reverse engineered pitch)

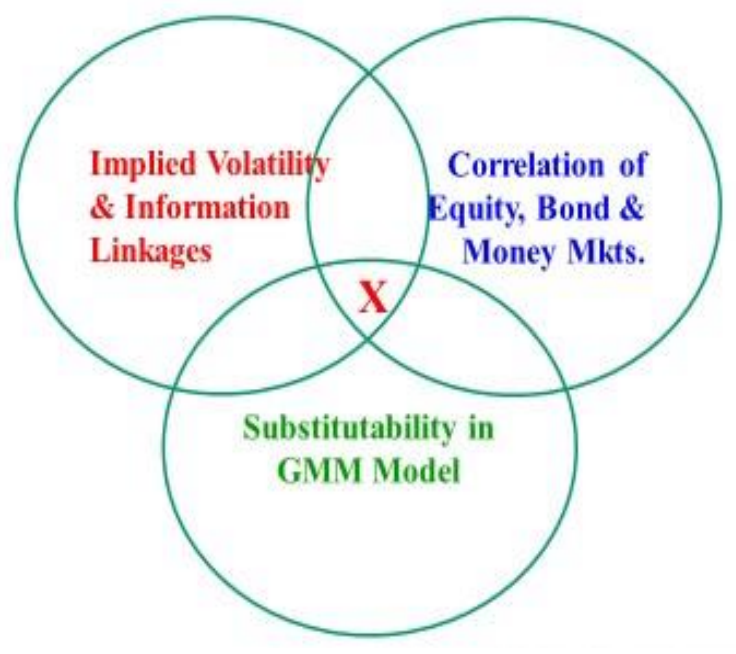

Figure 2. Mickey Mouse Diagram Characterising Novelty of Research Idea (for real pitch)

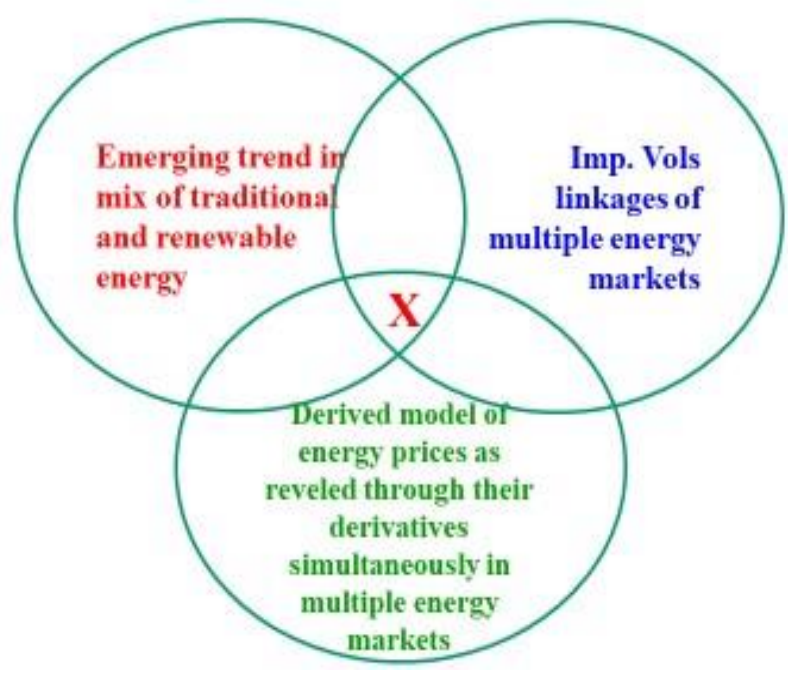




\section{References}

Black, F. \& Scholes, M. (1973) “The Pricing of Options and Corporate Liabilities”, Journal of Political Economy, 81(3): 637-654

Faff, R.W. (2015) "A Simple Template for Pitching Research", Accounting \& Finance, 55(2): 311-336

Faff, R.W. (2017) Pitching Research ${ }^{\circledR}$ Available at SSRN: http://ssrn.com/abstract=2462059 or http://dx.doi.org/10.2139/ssrn.2462 059 [latest version]

Faff, R.W. (2018) "Pitching Research", Available at SSRN: http://ssrn.com/ abstract $=2462059$

Fleming, J., Kirby, C. \& Ostdiek, B. (1998) "Information and volatility linkages in the stock, bond, and money markets", Journal of Financial Economics, 49(1): 111-137

Kodres, L. E. \& Pritsker, M. (2002) "A rational expectations model of financial contagion", The Journal of Finance, 57(2): 769-799

Rekker, S. (2016) "Converting planetary boundaries into action, a new approach to meeting global greenhouse gas targets: A pitch", Accounting and Management Information Systems, 15(1), 160-167

Salehudin, I. (2017) "Reverse engineering 'the pitching research template: a simple tool to help understand the academic literature", Accounting and Management Information Systems, 16(1): 203-210

Unda, L. A. (2015) "Board of director's characteristics and credit union financial performance: a pitch", Accounting \& Finance, 55(2): 353-360

Wallin, A., \& Spry, A. (2016) "The role of corporate versus product brand dominance in brand portfolio overlap: A Pitch", Accounting and Management Information Systems, 15(2), 434-439

Wang, K. (2009) "Volatility linkages of the equity, bond and money markets: an implied volatility approach", Accounting \& Finance, 49(1): 207-219 